\title{
ANALISIS PEMILIHAN SUPPLIER BAHAN BAKU PADA CV GENERAL TIMBER INDONESIA
}

\section{Lilis Supiani}

Program Studi Manajemen - Fakultas Ekonomi dan Bisnis

Universitas Muhammadiyah Gresik

\begin{abstract}
This study aims to determine the system of decision-making and priority criteria in supplier selection. Supplier selection is part of the supply chain. The role of suppliers affect the production process of a company as a supplier is a major business partner in the operation of the company's work. every manufacturing company has a standard priority suppliers so that it takes an analytical tool for decision-making. Method Analythical Hierarcy Process (AHP) is a decision making method of analysis used in decision-making with a systems approach, where decision-makers are trying to understand a condition of the system and help make predictions in decision-making. Distributing questioner to determine priority criteria CV General Timber supplier in Indonesia.

The results of evaluation research in the company's performance $C V$ General Timber Indonesia, there are five priorities, namely Cost supplier criteria with a weighting of $0.29 \%$, Quality 0,26\%, Quantity by 0.16\%, Delivery $0.15 \%$ and Flexibility of $0.13 \%$
\end{abstract}

Keywords: System decision making, Supplier Selection Analythical Hierarcy Process (AHP)

\section{PENDAHULUAN}

Pada dasarnya kepuasan konsumen itu suatu keadaan dimana kebutuhan, keinginan, serta harapan konsumen dapat terpenuhi melalui produk yang di gunakan (Nasution,2005). Perusahaan menciptakan produk tidak terlepas dari peran para supplier untuk memenuhi aspek kebutuhan proses produksinya, karena supplier merupakan mitra bisnis yang mempunyai peran penting dalam ketersediaan bahan pasokan yang dibutuhkan oleh perusahaan, kesalahan dalam pemilihan bahan baku supplier akan berdampak pada penurunan produktifitas perusahaan hal ini dikarenakan bahan baku merupakan salah satu faktor penting dalam kegiatan proses produksi karena berpengaruh langsung terhadap produk yang dihasilkan. Jika supplier kurang tanggap terhadap permintaan perusahaan maka akan terhentinya proses produksi akibat keterlambatan dalam pengiriman bahan baku, hal ini perusahaan harus memilih supplier yang sesuai dengan kriteria. Ada beberapa supplier yang masuk kriteria yang diinginkan oleh CV General Timber Indonesia, yaitu supplier yang dapat memberikan nilai efisiensi terbaik dengan kriteria yang diminta oleh perusahaan akan menjadi alternatif terbaik. CV General Timber Indonesia memilih tiga supplier untuk memenuhi pengadaannya yaitu PT Alam Salbach, PT Cipayung Jaya dan Rimba Kusuma Lestari karena 
mampu memenuhi keinginan yang sesuai dengan kriteria yang di inginkan oleh perusahaan tersebut.

Berdasarkan seluruh rangkaian proses opersional dibidang manufactur mulai dari pengadaan hingga menjadi output, peneliti akan membahas mengenai kriteria supplier dalam pengadaan di CV General Timber Indonesia dengan ketentuan memilih supplier yang mampu memasok bahan baku dengan kualitas dan kuantitas sesuai dengan pemenuhan perusahaan tersebut.

Industri pabrik CV General Timber Indonesia merupakan jenis usaha produksi kayu untuk export, perusahaan dituntut agar terus memperhatikan mengenai permintaan konsumen mulai dari kualitas, kuantitas dan pelayanannya. Terdapat masalah yang terjadi dalam pemilihan supplier seperti kemampuan supplier dalam mengirim barang, kualitas yang dikirim tidak sesuai dengan yang di inginkan perusahaan, akibatnya berdampak pada proses produksi dan keterlambatan dalam pengiriman barang kepada pihak pembeli sehingga mendapatkan klaim dari pihak pelanggan yang mengakibatkan timbul kekecewaan pelanggan dengan adanya masalah tersebut maka CV General Timber Indonesia memilih supplier PT Alam Salbach, PT Cipayung Jaya PT Rimba Kusuma Lestari yang sesuai dengan kriteria perusahaan dan diharapkan mampu memenuhi keinginan perusahaan dan menjadi mitra bisnis baik jangka pendek maupun jangka panjang.

Berkaitan dengan proses produksi dan penjualan yang meningkat pada CV General Timber Indonesia maka proses pengadaan bahan baku kayu yang terjadi dalam kurun tiga tahun terakhir antara lain sebagai berikut:

Tabel 1.1

Pengadaan Bahan Baku Kayu

\begin{tabular}{|c|c|}
\hline Tahun & $\begin{array}{c}\text { Total pengadaan } \\
\left(\mathrm{m}^{3}\right)\end{array}$ \\
\hline 2013 & 1716,12 \\
\hline 2014 & 2392,76 \\
\hline 2015 & 3378,4 \\
\hline
\end{tabular}

Sumber: data CV General Timber

Indonesia (2013 - 2015)

Ada alternatif pemilihan supplier yang digunakan untuk mengembangkan sistem pendukung keputusan salah satunya melalui metode analytical hierarchy process (AHP). Analytical hierarcy process merupakan teori yang didasarkan pada hubungan saling ketergantungan antara beberapa komponen (Dewayana dan Budi 2009). Metode AHP memiliki banyak keunggulan dalam menjelaskan proses pengambilan keputusan karena dapat digambarkan secara grafis, sehingga mudah dipahami oleh semua pihak yang terlibat dalam pengambilan keputusan (Marimin, 2004). Metode ini banyak diterapkan di berbagai bidang salah satunya untuk pemilihan supplier bahan baku (Pujawan: 2005). Dengan menggunakan metode AHP masalah tentang pemilihan supplier dapat disederhanakan dalam sebuah struktur hierarki sehingga akan lebih mudah dipahami.

Pemaparan permasalahan tersebut menjadi penelitian dalam upaya mendukung pengambilan keputusan mulai dari kriteria pemilihan supplier yang dibutuhkan oleh CV General Timber Indonesia hingga proses produksinya. Tujuan adanya penelitian ini adalah untuk mengetahui sistem pengambilan keputusan pada proses pengadaan 
bahan baku kayu dengan menggunakan pendekatan analytical hierarchy process (AHP), dan Faktor prioritas apa sajakah yang mempengaruhi sistem pengambilan keputusan dalam proses pengadaan untuk pemilihan supplier.

\section{KAJIAN PUSTAKA}

\section{Sistem Pengambilan Keputusan}

Sistem merupakan suatu kumpulan dari elemen elemen yang saling berinteraksi membentuk suatu kesatuan dalam interaksi yang kuat maupun yang lemah dan saling berhubungan untuk suatu tujuan yang sama (Robert, dan Murdick et al (1995 : 7). Pengambilan keputusan merupakan proses pemecahan masalah dengan menentukan beberapa alternatif untuk menetapkan suatu tindakan untuk mencapai tujuan yang diinginkan.

$$
\text { Pengambilan keputusan }
$$

dibutuhkan sistem pendukung keputusan untuk mendapatkan solusi permasalahan yang didukung dengan aplikasi teknologi komputer yang digunakan untuk menangani masalah yang tidak terstruktur agar mempercepat dalam pengambilan keputusan dengan tujuan pemilihan berbagai alternatif keputusan dengan menggunakan data dan model yang merupakan hasil dari pengolahan informasi yang diperoleh (Mc leod, 2004).

Adapun tahapan dalam pengambilan keputusan terdiri dari tiga fase yaitu :

1. Inteligence merupakan tahap dalam proses penelusuran dan mendeteksi dari lingkup dan pengenalan masalah, kemudian data yang didapat di olah dan dimasukkan, diproses, dan diuji untuk mengidentifikasi masalah.
2. Design merupakan pada tahap ini proses penemuan, pengembangan dan menganalisis alternatif tindakan yang bisa dilakukan, sehingga pada tahap ini mulai mengerti masalah dan menemukan solusi yang tepat dan di uji kelayakan solusi tersebut.

3. Choice, merupakan proses pemilihan berbagai alternatif tindakan yang mungkin bisa dilakukan, kemudian hasilnya di implementasikan ke dalam proses pengambilan keputusan.

\section{Pengadaan}

Salah satu komponen utama supply chain adalah pengadaan bagian Pengadaan menyediakan input barang/jasa yang dibutuhkan dalam kegiatan produksi maupun kegiatan lain di perusahaan sesuai dengan jumlah yang dibutuhkan untuk mencapai sasaran organisasi maupun perusahaan. Hal yang paling penting dalam pengadaan barang/jasa adalah memilih supplier, berlangsungnya kelancaran proses produksi suatu perusahaan sangat dipengaruhi oleh supplier, pemilihan supplier merupakan bagian dari supply chain, karena untuk mengefisienkan integrasi supplier, manufaktur, gudang dan penyimpanan sehingga barang yang diproduksi dan didistribusikan dalam jumlah, waktu, serta lokasi yang tepat untuk meminimalisasi biaya dan memberikan pelayanan terhadap kepuasan konsumen (simchi-levi, 2003). Definisi oleh the council of logistic management :

"Supply Chain Management is the systematic strategic of coordination of the traditional business funtions within the supply chain for the purpose of improvng the long- term performance of the individual 
company and the supply chain as a whole".

Supply chain merupakan jaringan yang merujuk kepada hubungan dimana sebuah organisasi akan mempertahankan rekan bisnisnya untuk mendapatkan sumber produksi dalam memenuhi kebutuhan konsumen. Tujuan dari supply chain adalah untuk memaksimalkan nilai yang dihasilkan dari keseluruhan (Chopra 2001).Pengadaan merupakan komponen utama dalam SCM. Efisiensi di bagian pengadaan akan memberikan kontribusi yang cukup dalam meningkatkan keuntungan perusahaan.

Supply chain management tidak hanya berorientasi pada urusan internal sebuah perusahaan tetapi menyangkut hubungan antar partner perusahaan / hubungsn external., karena pada intinya setiap perusahaan ingin memuaskan konsumen, dengan pengiriman yang tepat waktu, kualitas barang yang bagus saling bekerjasama untuk mencapai tujuan bersama.

Supply chain management (SCM) merupakan solusi terbaik untuk memaksimalkan produktivitas untuk perusahaan yang berbeda dengan cara meningkatkan persaingan dan keuntungan perusahaan secara keseluruhan termasuk customer dengan memenuhi permintaannya.

Adapun manfaat dari supply chain yaitu:

1. Mengurangi persediaan barang, karena persediaan merupakan aset paling besar dalam suatu perusahaan oleh karena itu usaha dan cara harus dikembangkan untuk menekan penimbunan barang digudang agar biaya dapat digunakan.
2. Menjamin kelancaran penyediaan barang mulai dari supplier, proses produksi, pemasaran hingga ke pelanggan.

3. Kualitas barang, tidak hanya ditentukan dari proses produksi tetapi dari segi bahan baku serta kualitas dari bahan tersebut hingga pengirimannya.

4 Mengurangi jumlah supplier dengan tujuan mengurangi ketidakseragaman,biaya negosiasi dan lain lain

Secara umum pada hakekatnya seluruh kegiatan yang mencangkup aliran material, informasi adalah keseluruhan dari SCM pada perusahaan manufaktur kegiatan utama yang termasuk dalam klasifikasi SCM adalah sebagai berikut :

1. Kegiatan merancang produk baru (product development) dipertimbangkan beberapa hal yang sesuai dengan permintaan konsumen/pelanggan. Oleh karena itu dibutuhkan riset pasar yang memadahi, produk yang dirancang harus mencerminkan ketersediaan dan sifat dari bahan baku itu sendiri, perancangan produk sedemikian rupa agar mudah dalam pengiriman.

2. Kegiatan dalam mendapatkan bahan baku (procurement, purchasing dan supply)untuk mendapatkan bahan baku harus melibatkan supplier karena supplier merupakan pemasok bahan baku untuk proses produksi.

3. Kegiatan dalam merencanakan produksi dan persediaan

4. Kegiatan dalam pengiriman produk (distribusi)

Pada intinya supply chain menekankan pada kepuasan konsumen dengan bekerjasama untuk 
menciptakan suatu produk dengan kualitas yang tinggi harga yang murah dengan ketepatan waktu dalam pengiriman. Ukuran performansi SCM meliputi :Kualitas tingkat kepuasan pelanggan, loyalitas terhadap pelanggan, tepat waktu, fleksibilitas sesuai dengan jumlah dan spesifikasi yang dibutuhkan.

Tujuan utama dalam pemilihan supplier adalah level teratas yang akan disusun menjadi level hierarky yang berisi kriteria dan sub kriteria dan alternatif pengambilan keputusan seperti pada gambar.

\section{Analytical Hierarchy Process (AHP)}

Analytical hierarchy process pertama kali dikembangkan pada tahun 1970 oleh seorang ahli matematika dari universitas pitsburg amerika serikat yang bernama Dr. Thomas L Saaty. Apabila suatu masalah dikatakan kompleks, maka dibutuhkan alat analisis yang berupa sistem pendukung keputusan untuk membuat keputusan masalah tersebut (Syaifullah 2010). Pada dasarnya proses pengambilan keputusan pada umumnya memilih suatu alternatif. AHP umumnya digunakan dengan tujuan untuk menyusun prioritas dari berbagai alternatif pilihan yang ada dan bersifat kompleks atau multi kriteria (Bourgeois: 2005)

AHP tidak hanya membantu dalam memilih keputusan tetapi juga dapat memberikan alasan yang jelas dan tepat (Turban 2005). Mengurangi masalah yang kompleks dan perbandingan berpasangan dengan menggunakan data, pengalaman dan peramalan yang akan memberikan hasil yang jelas dan akurat. AHP dalam perbandingannya menggunakan skala rasio untuk kriteria dan skoring alternative.

AHP menyelesaikan masalah yang kompleks maupun tidak terstruktur menjadi jelas dan menatanya menjadi sebuah hierarki. Setiap variabel untuk setiap kepentingan di beri nilai mengenai arti penting dari variabel tersebut secara relatif kemudian setiap variabel akan berperan untuk mempengaruhi hasil pada sistem tersebut (Marimin 2004).

Kelebihan model AHP dalam pengambilan keputusan (Saaty 1994)adalah terletak pada kemampuannya dalam memecahkan permasalahan yang multi objektives dengan multi kriteria dan bersifat fleksibel dan mampu menangkap tujuan dan beberapa kriteria dalam sebuah hierarki, kurang lengkapnya data tertulis dan data kuantitatif mengenai permasalahan tidak mempengaruhi kelancaran dalam prses pengambilan keputusan karena penilaian merupakan sintesis pemikiran berbagai sudut pandang responden

Selain mempunyai kelebihan model AHP juga mempunyai kekurangan yaitu model AHP bergantung pada persepsi pada orang yang ahli dalam bidang tersebut yang akan menentukan hasil akhir dari model AHP ini tidak ada, apabila seorang ahli tersebut memberikan penilaian yang keliru terhadap persepsi tersebut.

Kriteria yang dapat mempengaruhi kinerja supplier dalam setiap kelompok maka ditentukan oleh masing masing bobot. Bobot dari setiap kriteria ditentukan oleh hasil dari masing masing perbandingan setiap kriteria, untuk mengetahui kriteria dari supplier maka perlu digunakan nilai 
numerik yang diperoleh dari skala perbandingan.

\section{METODE PENELITIAN}

Dalam penelitian ini menggunakan pola kualitatif deskriptif. Obyek penelitian dalam penelitian ini adalah CV General Timber Indonesia berada di Jl. Kapten Darmo Sugondo -Karang Kering, Gresik, Jawa Timur. Adapun fokus dalam penelitian ini adalah pada pemilihan supplier untuk pemilihan bahan baku.

Responden dalam penelitian ini hanya 5 orang dari total 73 tenaga kerja, yang terdiri masing-masing orang yang berkompeten dalam bidangnya. Masing masing terdiri dari (1) Manajer CV General Timber Indonesia, (2) Bagian Pengadaan, (3) Kepala Bagian Produksi, (4) Bagian Persediaan, (5) Bagian Quality Control.

Data primer diperoleh dari hasil wawancara dan diskusi dengan atasan langsung di CV General Timber Indonesia, observasi langsung ke tempat yang diteliti, Sedangkan data sekunder diperoleh dari studi pustaka dan data yang diperoleh dari tempat penelitian berupa gambaran umum tempat penelitian.

\section{HASIL PENELITIAN}

Proses pengadaan barang dilakukan dengan cara survei langsung kepada tempat yang akan memasok bahan baku kepada perusahaan tersebut.

Langkah yang dilakukan setelah masalah tersebut teridentifikasi kemudian memecahkan unsur tersebut hingga tidak mungkin dapat dipecahkan lebih lanjut untuk mendapatkan hasil yang akurat.

Kriteria dan sub kriteria pemilihan supplier dengan metode AHP disusun dengan hierarky untuk mendapatkan kriteria yang dibutuhkan oleh perusahaan. Masalah dalam pemilihan supplier pada CV GTI disusun berdasarkan level hierarky.

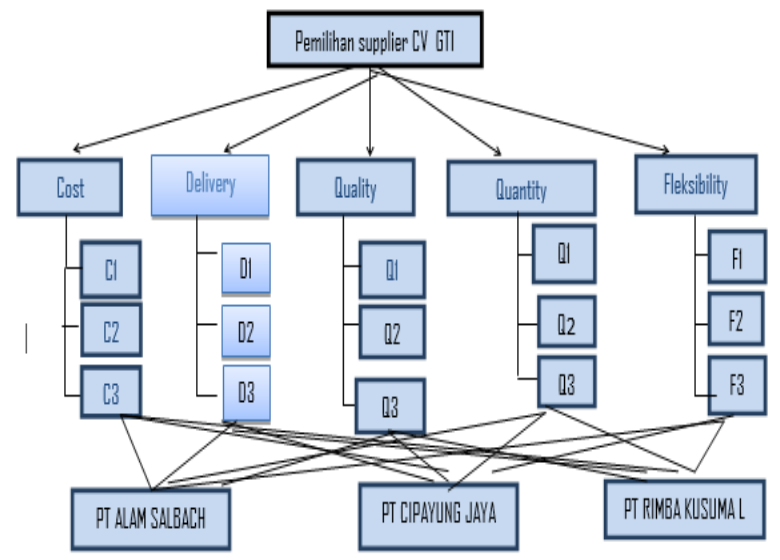

Gambar 4.1

Struktur Hierarky Pada CV GTI

Tabel.4.1

Bobot Kriteria Dalam Pemilihan Supplier

\begin{tabular}{|l|c|c|}
\hline \multicolumn{1}{|c|}{ Kriteria } & Bobot & $\begin{array}{c}\text { Priorita } \\
\text { s }\end{array}$ \\
\hline Harga & 0,29 & 1 \\
\hline Kualitas & 0,26 & 2 \\
\hline Kuantitas & 0,16 & 3 \\
\hline Pengiriman & 0,15 & 4 \\
\hline Fleksibilitas & 0,13 & 5 \\
\hline
\end{tabular}

Sumber: hasil pengolahan dengan AHP

Dari tabel diatas menunjukkan bahwa kriteria pemilihan supplier pada CV General Timber Indonesia prioritas utama adalah harga dengan bobot 0,29, kualitas dengan bobot 0,26 , kuantitas dengan bobot 0,16 , pengiriman dengan bobot 0,15 dan fleksibilitas dengan bobot 0,13

Hasil analisis dengan AHP kriteria yang berpengaruh pada CV General Timber Indonesia adalah harga dengan bobot sebesar 0,29\%. Selanjutnya di ikuti oleh kualitas dengan bobot $0,26 \%$, kriteria kuantitas sebesar $0,16, \%$, kriteria 
pengiriman sebesar $0,15 \%$ dan kriteria fleksibilitas sebesar $0,13 \%$

Tingginya bobot harga untuk kriteria pemilihan supplier berarti menunjukkan bahwa CV General Timber Indonesia lebih mengutamakan harga untuk bahan baku yang digunakan. Hal ini dikarenakan semakin lama harga bahan baku semakin mahal karena bahan baku yang digunakan dari hasil alam jadi tidak setiap saat ada.

Sub kriteria harga dalam pemilihan supplier mencakup tiga hal yaitu harga kompetitif ,cara pembayaran, rincian harga dari sub kriteria tersebut masing masing memiliki bobot cara pembayaran dengan bobot 0,63 , sub kriteria rincian harga mempunyai bobot 0,26 dan harga kompetitif mempunyai bobot 0,11 sedangkan Pemilihan alternatif supplier yang paling baik untuk penyedia bahan adalah supplier PT Cipayung Jaya sebesar 0,68 ,PT Alam Salbach mempunyai bobot sebesar 0,25 dan PT Rimba Kusuma Lestari mempunyai bobot sebesar 0,7. Hasil ini menunjukkan bahwa supplier PT Cipayung Jaya yang dipilih oleh perusahaan untuk dijadikan rekan mitra kerja untuk jangka panjang karena secara keseluruhan supplier tersebut mempunyai bobot nilai tertinggi dibandingkan dengan supplier yang lainnya.

\section{KESIMPULAN DAN SARAN Kesimpulan}

Kesimpulan dari penelitian ini mengenai Analisis Pemilihan Supplier Pada CV General Timber Indonesia adalah sebagai berikut:

1. Sistem pengambilan keputusan pada proses pengadaan bahan baku pada CV General Timber indonesia dengan menggunakan metode Analytical Hierarcy Process untuk memecahkan masalah yang kompleks atau tidak terstruktur dalam sub sub masalah kedalam bentuk hierarky agar masalah dalam pemilihan supplier mampu terselesaikan dengan baik dan terstruktur.

2. Faktor prioritas dalam pemilihan supplier di CV General Timber Indonesia adalah (1) cost karena perusahaan memilih supplier yang menawarkan harga yang kompetitif dibandingkan dengan perusahaan yang lain, (2) quality,dengan kualitas bahan baku yang bagus maka output yang dihasilkan juga berkualitas, (3) quantity jumlah yang di kirim harus sesuai dengan yang telah di sepakati (4) delivery proses pengiriman harus sesuai dengan yang telah di sepakati oleh kedua belah pihak atau tepat waktu,(5) flexibility perusahaan harus bisa memenuhi perubahan pemintaan dalam pengadaan bahan baku.

\section{Keterbatasan dan Rekomendasi}

Setelah mempelajari terkait hasil dari penelitian ini maka terdapat keterbatasan dan rekomendasi untuk penelitian selanjutnya yang dijelaskan sebagai berikut :

1. Adanya keterbatasan peneliti untuk melakukan analisis mendalam terkat supplier penyedia bahan baku di CV General Timber Indonesia bagi peneliti selanjutnya peneliti bisa menggunakan kriteria-kriteria lain yang sesuai dengan kebijakan perusahaan masing-masing. Selain itu, untuk mengurangi subyektivitas penilaian responden, terutama untuk mengurangi ketidaktepatan dan ketidakpastian responden dalam memetakan 
persepsinya ke dalam angkaangka numerik, peneliti bisa menggunakan metode fuzzy AHP.

2. Pemilihan supplier pada CV General Timber Indonesia sudah baik dan bahan baku untuk proses produksi sudah sesuai dengan kualitas yang diharapkan oleh CV General Timber Indonesia dan untuk supplier perlu di pantau performasinya secara berkala agar supplier tersebut tetap menjadi mitra kerja yang baik pada CV General Timber Indonesia

\section{DAFTAR PUSTAKA}

Bayton 1993,Sistem

KeputusanEdisi

Pendukung

Penerbit Pertama

Yogyakarta.

Graha Ilmu

Dewayana dan Budi 2009

Pengenalan Sistem Pendukung Keputusan dengan menggunakan metode Analythical Hierarcy Process.

I Nyoman Pujawan Edisi Kedua Penerbit Intitut Teknologi Sepuluh Nopember

Marimin. Teknik Dan Pengambilan Keputusan Kriteria Majemuk, Jakarta: Grasindo, 2005

Mcleod,

Raymond.2004

Management Information Systems. 8th Edition, New Jersey : Prentice Hall, Inc.

Pujawan 2005 electronic procurement and its role in achievieng manufacturing strategic objective. Intenational journal of logistic system and management
Robert, dan Murdick et al 1995 : 7 strategic purchasing : A history and review of the literature .International jurnal of purchasing and material management

Simchi-Levi, 2003 Supply Chain Management I Nyoman Pujawan Edisi Kedua Penerbit Intitut Teknologi Sepuluh Nopember

Syaifullah 2010 Pengenalan Metode Analitycal Hierarchy Process, Teknik Informatika STMIK Budi Darma Medan

Turban, 2005 Implementasi Aplikasi Decision Support System Dengan Metode Analytical Hierarcy Process (Ahp) Untuk Penentuan Jenis Supplier,Jurnal Fakultas Teknologi Industri, Jurusan Teknik Informatika, Universitas Kristen Petra Surabaya 